\title{
Evaluation of Interferon Gamma Release Assay in the Diagnosis of Active and Latent Tuberculosis among Patients and Contacts
}

Corresponding Author Yousra A. El-Maradny

Mobile:

01202330002

E mail:

hiph.ymaradny@alexu. edu.eg

Key words:

Tuberculosis

Tuberculin skin test, Ziehl-Neelsen stain, QuantiFERON-TB

Gold In-Tube test

\author{
Yousra A. El-Maradny, Heba Selim \\ Department of Microbiology, High Institute of Public Health, Alexandria University, \\ Alexandria, Egypt.
}

Background and study aim: To date, tuberculosis (TB) is a global health emerging disease. Early detection of TB infection is critical to start therapy and stop increasing the prevalence of TB cases. The presence of sensitive, noninvasive, rapid and cheap method for diagnosing active and latent TB is very crucial to control TB transmission.The current study aims to compare the results of Ziehl-Neelsen (ZN) and tuberculin skin test (TST or Mantoux) with the QuantiFERON-TB Gold in-tube Test (QFT-GIT) in the diagnosis of active TB and latent infection.

Patients and method: The study included 90 participants divided into 45 clinically and microbiologically diagnosed patients with pulmonary tuberculosis (PTB) and 45 close contacts to PTB patients. Both groups examined clinically, and subjected to three diagnostic tests; ZN, Mantoux, and QFTGIT.
Results: The TST was positive in $95.6 \%$ and $42.2 \%$ of patients and contacts, respectively. Out of the screened TB patients and contacts, the positive QFTGIT was found among $86.7 \%$ and $68.9 \%$, respectively. The total agreement between QFT-GIT and the Mantoux was $71.11 \%$. Positive concordant results (QFT+/TST+) were observed in $86.9 \%$, while negative concordant results (QFT-/TST-) were detected in $37.9 \%$ of patients and contacts.

Conclusion: The evaluation results of the QFT-GIT with ZN and Mantoux showed high sensitivities but relatively low specificities. The specificity of QFT-GIT was improved by modifying the cut off values to higher levels. Latent tuberculosis infection (LTBI) was likely to occur when both QFT-GIT and TST were positive .

\section{INTRODUCTION}

Tuberculosis (TB) is a public health problem that infects about millions of individuals each year. Nowadays, TB is in the list of the top 10 diseases causing deaths globally, and it was ranked above the human immunedeficiency virus (HIV) [1]. In 2019, the World Health Organization (WHO) reported that around ten million new TB cases and 1.5 million people died from TB worldwide [1].

In Egypt, tuberculosis is the third predominant communicable disease after hepatitis $\mathrm{C}$ and schistosomiasis $[2,3]$. There are 12 thousand reported incident cases of TB in Egypt in 2018 [1]. In 1993, TB was considered a global health emergency by the WHO. Between 2006 to 2015, the WHO implement a plan to stop TB called (Stop TB Partnership), which aimed to protect 14 million lives [4]. After that, a new strategy was launched to end TB by 2030 through decreasing new TB cases by $80 \%$ [5].

Mycobacterium tuberculosis (Mtb) an acid-fast bacillus transmitted by airborne and causing TB infection. The detection of pulmonary TB depends on the symptoms, chest imaging, detection of acid-fast bacilli (AFB), mycobacteria culturing, and nucleic acid amplification (NAA) techniques [6]. 
Mycobacterium tuberculosis infection without any active TB symptoms is stated as a latent tuberculosis infection (LTBI) [7]. Tuberculin is a purified protein derivative (PPD) taken from tubercle bacilli. Tuberculin skin test (TST or Mantoux) is used worldwide and counted as the best method to diagnose LTBI. However, Mantoux is not considered a "gold standard" because of the personal variation in reading the results and the possibility of false results $[\mathbf{8 , 9}$.

Interferon-gamma release assays (IGRAs) are more novel methods to detect LTBI. IGRAs tested the cell-mediated immune reaction from the in-vitro collected blood sample. The test is using specific mycobacterial antigens (ESAT6/CFP-10/TB-7.7(p4)) to detect the interferongamma (IFN- $\gamma)$ produced from $\mathrm{T}$ cells after exposing to Mtb because of delayed hypersensitivity response [10]. The U.S. Food and Drug Administration (FDA) approved QuantiFERON®-TB Gold In-Tube test (QFTGIT) in the detection of both active and latent tuberculosis [11].

The current study compared the ability of QFTGIT, TST and Ziehl-Neelsen (ZN) stain to detect pulmonary TB (PTB) and screening LTBI in close contacts to TB patients .

\section{PATIENTS AND METHODS}

\section{Study design:}

The study was a cross-sectional design that included 90 participants, forty-five patients with PTB (the patients were included according to their clinical symptoms, $\mathrm{ZN}$ stain and mycobacterium culture), and forty-five close contacts to the confirmed PTB patients with duration of exposure for more than two weeks. The study was conducted in El Maamora Chest Hospital, Alexandria, Egypt. Chart of the study design and main results are shown in (Figure 1). A full questionnaire was filled for each TB patient and another one for their contacts. Each questionnaire contained the patient's data (serial number, robe number, date of entry, name, age, gender, job, and address), chance of TB infection, vaccination with Bacillus CalmetteGuérin (BCG), clinical picture and other diseases (diabetes, hepatitis $\mathrm{C}$ and $\mathrm{B}$ viruses and Human immunodeficiency virus infection (HIV)). Finally, we performed one year follow up for contacts of TB patients. Informed consent was gained from each subject included in the study.

\section{Sputum for acid-fast bacilli:}

Every suspected PTB and contact should submit three sputum samples "on the SPOT - early MORNING - on the SPOT" for microscopy.

The samples were spread over microscopic slides, heat-fixed, stained, and decolorized. Finally, the slides were observed under the microscope for the detection of AFB according to the standard protocol $[\mathbf{1 2 , 1 3 ]}$.

\section{Sputum cultures of mycobacteria:}

For every suspected patient with PTB clinical symptoms and abnormal x-ray, an Egg-based Löwenstein-Jensen (LJ) culture was done. Using Petroff's method in concentration and decontamination of sputum samples [13]. Observation of cultures was done 48-72 hours after inoculation to detect atypical mycobacterium or any contaminants, any contaminated culture was discarded. Mtb typical colonies are crumbly, rough, non-pigmented, waxy and slow growers appear two to three weeks after inoculation. ZN staining should be performed for the colony with doubtful morphology [13].

\section{Tuberculin skin test (TST):}

Mantoux test was performed following the manufacturer procedure of Tuberculin diluted (5 Tuberculin Units/0.1 ml) (Span Diagnostics LtdIndia). In brief, $0.1 \mathrm{ml}$ from the vial was intradermally injected in the forearm. With a black marker pen, a mark was made around the edges of induration before measuring. Then, the induration was measured after 48-72 hours in millimeters. The test was positive when the induration is raised or swelled and measured more than or equal to $5 \mathrm{~mm}$, according to the criteria listed in (Table 1).

\section{QuantiFERON@-TB Gold In-Tube test (QFT- GIT):}

QFT test was performed for all patients and contacts as instructed in the leaflet in two stages. First, the whole blood was drawn then incubated for 16 to 24 hours in $37 \mathrm{oC}$, after which, plasma was collected and stored at $-80 \mathrm{oC}$. Second, the collected plasma was tested to detect the interferon- $\gamma($ IFN- $\gamma)$ released in response to the peptide antigens by ELISA. 


\section{Statistical analysis of the data:}

Data were fed to the computer and analyzed using IBM SPSS software package version 20.0 [14]. Qualitative data were described using numbers and percentages. Quantitative data were described using mean and standard deviation and median. A Chi-square test was used to compare different groups regarding categorical variables. Correction for chi-square was conducted using Fisher's exact test or Monte Carlo correction when more than $20 \%$ of the cells have expected count less than 5. The distributions of quantitative variables were tested for normality using the Shapiro-Wilk test, KolmogorovSmirnov test, and D'Agstino test, also Histogram and QQ plot was used for the vision test. Parametric tests were applied only if it reveals normal data distribution. The comparison between two independent populations was done using an independent t-test for normally distributed data. Agreement of the different predictive with the outcome was used and was expressed in sensitivity, specificity, positive predictive value (PPV), negative predictive value (NPV), and accuracy. The significance of the obtained results were judged at the 5\% level [15].

The receiver operating characteristic curve (ROC) was plotted to analyze a recommended cutoff, the area under the ROC curve denotes the diagnostic performance of the test. Area more than $50 \%$ gives acceptable performance and area about $100 \%$ is the best performance for the test.

\section{RESULTS}

As presented in (Table 2), there were no statistically significant relations with QFT-GIT results and age, gender, BMI, smoking history, and residence. It found that $95.6 \%$ of active TB patients had cough, $17.8 \%$ were diabetic, $2.2 \%$ had been infected with $\mathrm{HCV}$, and $2.2 \%$ had been infected with HIV. On the other hand, only $4.4 \%$ of contacts had cough, and $11.1 \%$ were diabetic.
In this study, $95.6 \%$ out of 45 PTB patients and $42.2 \%$ out of 45 contacts were TST positive (Figure 2a). On the other hand, $86.7 \%$ and $68.9 \%$ of TB patients and contacts were QFTGIT positive, respectively, shown in (Figure 2b). The concordant and negative concordant data of QFT-GIT and TST were documented in (Table $3)$.

The TST sensitivity and specificity to $\mathrm{ZN}$ were $100 \%$ and $57.1 \%$, respectively. The PPV and NPV of TST among patients and contacts was $67.21 \%$ and $100.00 \%$, respectively. The overall agreement between TST and ZN was $77.78 \%$. These results were statistically significant (Pvalue $=0.000)$ (Table 4).

The QFT-GIT sensitivity and specificity against ZN smear were $85.37 \%$ and $28.6 \%$, respectively (Table 5). QFT-GIT sensitivity and specificity against TST were $85.5 \%$ and $39.3 \%$, respectively. Moreover, the positive (PPV) and negative predictive value (NPV) of QFT-GIT across patients and contacts were $75.71 \%$ and $55.0 \%$, respectively. The total agreement between QFT-GIT and the TST was $71.11 \%$. These results were statistically significant (Pvalue $=0.004)($ Table 6$)$.

After a one-year follow-up of contacts, we found that two cases had developed active PTB; these were two females with Mantoux test induration $\geq$ $10 \mathrm{~mm}$ and positive QFT-GIT result.

\section{ROC curve analysis for QFT-GIT results:}

The ROC curve for QFT-GIT shows that AUC was 0.730 , the significance level $\mathrm{P}$ (Area=0.5) was 0.0001 , and the $95 \%$ confidence interval was 0.626 to 0.819 .

From the ROC curve, we found that the sensitivity and the specificity of QFT-GIT were $78.33 \%$ and $65.52 \%$, respectively, when the cutoff value was $>1.53 \mathrm{IU} / \mathrm{ml}$ as shown in (Figure 3 ). 


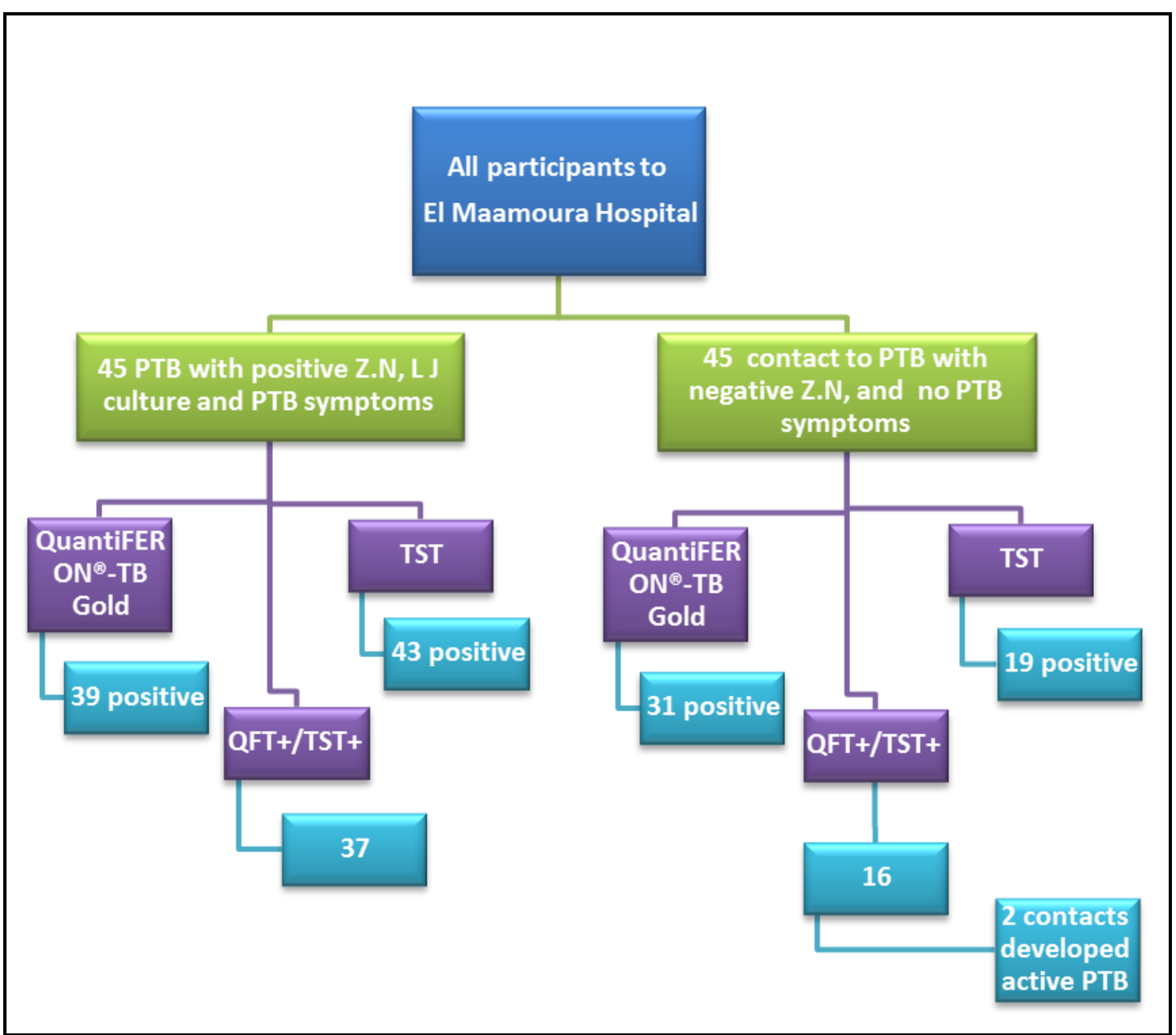

Figure (1): Flow chart of the study design and baseline patient information.

- Yes No

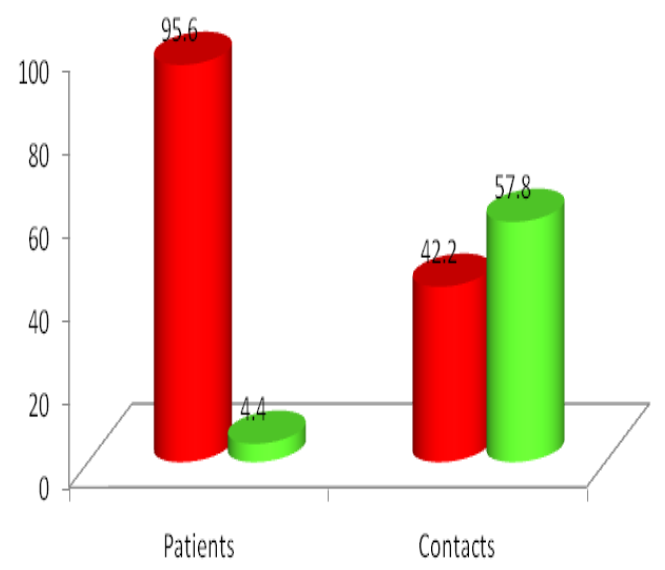

(a)
- Yes $\amalg$ No

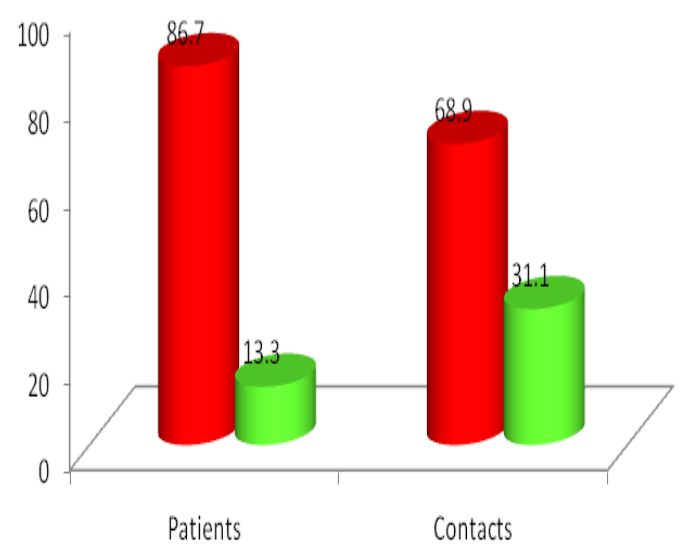

(b)

Figure (2): Charts representing the positive and negative results of a) TST and b) QFT-GIT among TB patients and contacts. 


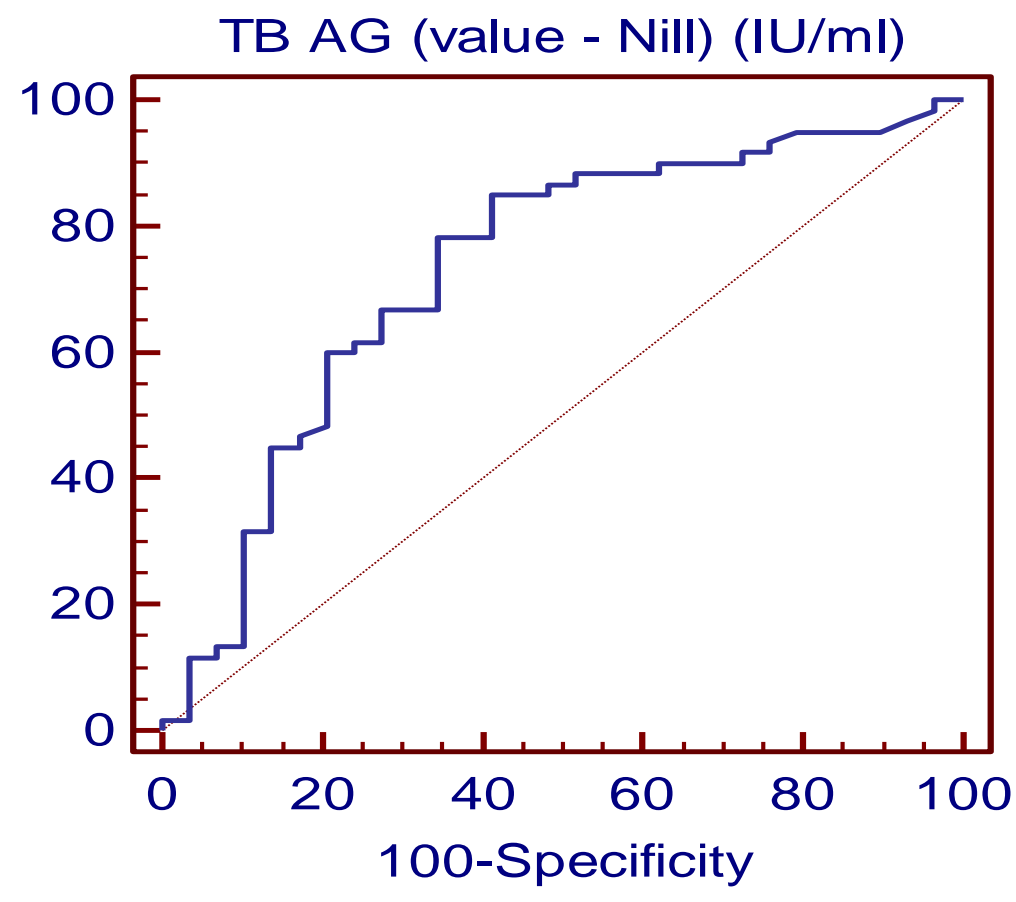

Figure (3): ROC curve analysis for QFT-GIT results.

Table (1): Criteria for a Positive Tuberculin Skin Test by Risk Group. [17,27].

\begin{tabular}{|c|c|c|}
\hline Reaction $\geq 5 \mathrm{~mm}$ induration & Reaction $\geq 10 \mathrm{~mm}$ induration & Reaction $\geq 15 \mathrm{~mm}$ induration \\
\hline $\begin{array}{l}\text { human immunodeficiency } \\
\text { infection }\end{array}$ & $\begin{array}{l}\text { Children younger than four years or } \\
\text { infants }\end{array}$ & $\begin{array}{l}\text { People with no risk factors for } \\
\text { tuberculosis }\end{array}$ \\
\hline organ transplantation & \begin{tabular}{|ll}
$\begin{array}{l}\text { Mycobacteriology } \\
\text { personnel }\end{array}$ & laboratory \\
\end{tabular} & \\
\hline $\begin{array}{l}\text { Receiving of immunosuppressant } \\
\text { medications }\end{array}$ & $\begin{array}{l}\text { Children younger than four years or } \\
\text { infants }\end{array}$ & \\
\hline $\begin{array}{l}\text { Recent contacts } \\
\text { tuberculosis patient }\end{array}$ & $\begin{array}{l}\text { Residents and employees in areas } \\
\text { such as; prisons and jails, nursing } \\
\text { homes, hospitals, homeless shelters, } \\
\text { low-income populations }\end{array}$ & \\
\hline $\begin{array}{llr}\text { Fibrotic changes on } & \text { chest } \\
\text { radiography in previously } & \text { TB } \\
\text { infected person } & & \\
\end{array}$ & $\begin{array}{l}\text { People with certain clinical } \\
\text { conditions such as; malnutrition, } \\
\text { chronic renal failure, diabetes } \\
\text { mellitus, gastrectomy or intestinal } \\
\text { bypass, malignancy, silicosis }\end{array}$ & \\
\hline & $\begin{array}{l}\text { Immigrants from developing countries } \\
\text { that had high TB prevalence }\end{array}$ & \\
\hline & $\begin{array}{l}\text { People who use injection with high- } \\
\text { risk substances }\end{array}$ & \\
\hline
\end{tabular}


Table (2): Different studied parameters among TB patients and contacts.

\begin{tabular}{|c|c|c|c|c|c|c|c|}
\hline \multirow{2}{*}{\multicolumn{2}{|c|}{ Variables }} & \multicolumn{2}{|c|}{$\begin{array}{c}\text { Patients } \\
(\mathrm{N}=45)\end{array}$} & \multicolumn{2}{|c|}{$\begin{array}{c}\text { Contacts } \\
(\mathrm{N}=45)\end{array}$} & & \multirow{3}{*}{$\begin{array}{c}P \text {-value } \\
0.535 \\
\end{array}$} \\
\hline & & $\mathbf{N}$ & $\%$ & $\mathbf{N}$ & $\%$ & & \\
\hline Age & Mean \pm SD & \multicolumn{2}{|c|}{$42.75 \pm 14.58$} & \multicolumn{2}{|c|}{$40.95 \pm 12.80$} & T test $=0.623$ & \\
\hline Sex & Male & 31 & 69 & 10 & 22 & $X^{2}=19.76$ & $0.000 *$ \\
\hline \multirow{3}{*}{ Marital state } & Married & 30 & 66.7 & 38 & 84.4 & \multirow{3}{*}{$X^{2}=4.741$} & \multirow{3}{*}{0.093} \\
\hline & Not married & 13 & 28.9 & 7 & 15.6 & & \\
\hline & Widowed & 2 & 4.4 & 0 & 0 & & \\
\hline BCG vaccination & Vaccinated (with scar) & 42 & 93.3 & 45 & 100.0 & & 0.242 \\
\hline \multirow{4}{*}{$\mathbf{B M I} \uparrow$} & Under-weight $(<18.5)$ & 5 & 11.1 & 0 & 0 & & \multirow{4}{*}{$0.001 *$} \\
\hline & Normal $(18.5$ to $<25)$ & 28 & 62.2 & 16 & 35.6 & & \\
\hline & Over-weight $(25$ to $<30)$ & 10 & 22.2 & 18 & 40.0 & & \\
\hline & Obese $(>30)$ & 2 & 4.5 & 11 & 24.4 & & \\
\hline Smoking & Yes & 29 & 64.4 & 6 & 13.3 & $X^{2}=24.732$ & $0.000^{*}$ \\
\hline \multirow{2}{*}{ Residence } & Urban & 36 & 80.0 & 45 & 100.0 & \multirow{2}{*}{$X^{2}=10.000$} & \multirow{2}{*}{$0.002 *$} \\
\hline & Rural & 9 & 20.0 & 0 & 0.0 & & \\
\hline Diabetes & Diabetic & 8 & 17.8 & 5 & 11.1 & & 0.368 \\
\hline $\mathrm{HCV}$ & HCV positive & 1 & 2.2 & 0 & 0.0 & & 0.315 \\
\hline HIV & HIV positive & 1 & 2.2 & 0 & 0.0 & & 0.315 \\
\hline Z.N. smear & Positive & 41 & 91.1 & 0 & 0.0 & & $0.000^{*}$ \\
\hline TST results & Positive & 43 & 95.6 & 19 & 42.2 & $X^{2}=31.798$ & $0.000^{*}$ \\
\hline QFT-GIT results & Positive & 39 & 86.7 & 31 & 68.9 & $X^{2}=4.11$ & $0.043^{*}$ \\
\hline $\begin{array}{c}\text { Interferon gamma } \\
\text { levels (IU/ml) }\end{array}$ & Mean \pm SD & \multicolumn{2}{|c|}{$4.90 \pm 3.44$} & \multicolumn{2}{|c|}{$3.55 \pm 3.63$} & $\begin{array}{c}\text { Mann Whitney } \\
\text { test }=1.755\end{array}$ & 0.079 \\
\hline
\end{tabular}

*significant $\mathrm{p}<0.05$

$\dagger$ BMI body mass index $=$ weight $(\mathrm{kg}) /(\text { height }(\mathrm{m}))^{2}$ [28].

Table (3): Different studied parameters among TB patients and contacts.

\section{A- Patients}

\begin{tabular}{|c|c|c|c|c|c|c|c|}
\hline \multirow{3}{*}{ QFT-GIT } & \multicolumn{4}{|c|}{ TST induration $\geq 5 \mathrm{~mm}$} & \multirow{2}{*}{\multicolumn{2}{|c|}{ Total }} & \multirow{3}{*}{$p$-value } \\
\hline & \multicolumn{2}{|c|}{ Negative } & \multicolumn{2}{|c|}{ Positive } & & & \\
\hline & $\mathbf{N}$ & $\%$ & $\mathbf{N}$ & $\%$ & $\mathbf{N}$ & $\%$ & \\
\hline Negative & 0 & 0.0 & 6 & 14.0 & 6 & 13.3 & \multirow{3}{*}{0.570} \\
\hline Positive & 2 & 100.0 & 37 & 86.0 & 39 & 86.7 & \\
\hline Total & 2 & 100.0 & 43 & 100.0 & 45 & 100.0 & \\
\hline
\end{tabular}

\section{B- Contacts}

\begin{tabular}{|c|c|c|c|c|c|c|c|}
\hline \multirow{3}{*}{ QFT-GIT } & \multicolumn{4}{|c|}{ TST induration $\geq 5 \mathrm{~mm}$} & \multirow{2}{*}{\multicolumn{2}{|c|}{ Total }} & \multirow{3}{*}{$p$-value } \\
\hline & \multicolumn{2}{|c|}{ Negative } & \multicolumn{2}{|c|}{ Positive } & & & \\
\hline & $\mathbf{N}$ & $\%$ & $\mathbf{N}$ & $\%$ & $\mathbf{N}$ & $\%$ & \\
\hline Negative & 11 & 42.3 & 3 & 15.8 & 14 & 31.1 & \multirow{3}{*}{$0.032 *$} \\
\hline Positive & 15 & 57.7 & 16 & 84.2 & 31 & 68.9 & \\
\hline Total & 26 & 100.0 & 19 & 100.0 & 45 & 100.0 & \\
\hline
\end{tabular}

*significant $\mathrm{p}<0.05$

\section{C- Patient and contact groups.}

\begin{tabular}{|c|c|c|c|c|c|c|c|}
\hline \multirow{3}{*}{ QFT-GIT } & \multicolumn{4}{|c|}{ TST induration $\geq 5 \mathrm{~mm}$} & \multirow{2}{*}{\multicolumn{2}{|c|}{ Total }} & \multirow{3}{*}{$p$-value } \\
\hline & \multicolumn{2}{|c|}{ Negative } & \multicolumn{2}{|c|}{ Positive } & & & \\
\hline & $\mathbf{N}$ & $\%$ & $\mathbf{N}$ & $\%$ & $\mathbf{N}$ & $\%$ & \\
\hline Negative & 11 & 39.3 & 9 & 14.5 & 20 & 22.2 & \multirow{3}{*}{$0.004 *$} \\
\hline Positive & 17 & 60.7 & 53 & 85.5 & 70 & 77.8 & \\
\hline Total & 28 & 100.0 & 62 & 100.0 & 90 & 100.0 & \\
\hline
\end{tabular}

*significant $\mathrm{p}<0.05$

El-Maradny and Selim, Afro-Egypt J Infect Endem Dis 2021;11(1):69-77

https://aeji.journals.ekb.eg/

http://mis.zu.edu.eg/ajied/home.aspx 
Table (4): Sensitivity, specificity, positive predictive value (PPV) and negative predictive value (NPV) of TST against ZN smear among TB patients and contact group.

\begin{tabular}{|c|c|c|c|c|c|c|c|c|c|c|}
\hline \multirow{3}{*}{$\begin{array}{c}\text { TST } \\
\text { induration }(\geq \\
5 \mathrm{~mm}) \\
\end{array}$} & \multicolumn{6}{|c|}{$\mathbf{Z N}$} & \multirow{3}{*}{ Sensitivity } & \multirow{3}{*}{ Specificity } & \multirow{3}{*}{ PPV } & \multirow{3}{*}{ NPV } \\
\hline & \multicolumn{2}{|c|}{ Negative } & \multicolumn{2}{|c|}{ Positive } & \multicolumn{2}{|c|}{ Total } & & & & \\
\hline & $\mathbf{N}$ & $\%$ & $\mathbf{N}$ & $\%$ & $\mathbf{N}$ & $\%$ & & & & \\
\hline Negative & 28 & 57.1 & 0 & 0.0 & 28 & 31.1 & \multirow{2}{*}{100} & \multirow{2}{*}{57.1} & \multirow{2}{*}{67.21} & \multirow{2}{*}{100.0} \\
\hline Positive & 21 & 42.9 & 41 & 100 & 62 & 68.9 & & & & \\
\hline Total & 49 & 100.0 & 41 & 100.0 & 90 & 100.0 & $\begin{array}{l}\text { Overall A } \\
\text { Kappa }\end{array}$ & $\begin{array}{l}\text { greement } \\
=0.569,\end{array}$ & racy & 7.78 \\
\hline
\end{tabular}

*significant $\mathrm{p}<0.05$

Table (5): Sensitivity, specificity, positive predictive value (PPV) and negative predictive value (NPV) of QFT-GIT against ZN smear among TB patients and contact group .

\begin{tabular}{|c|c|c|c|c|c|c|c|c|c|c|}
\hline \multirow{3}{*}{ QFT-GIT } & \multicolumn{6}{|c|}{$\overline{Z N}$} & \multirow{3}{*}{ Sensitivity } & \multirow{3}{*}{ Specificity } & \multirow{3}{*}{ PPV } & \multirow{3}{*}{ NPV } \\
\hline & \multicolumn{2}{|c|}{ Negative } & \multicolumn{2}{|c|}{ Positive } & \multicolumn{2}{|c|}{ Total } & & & & \\
\hline & $\mathbf{N}$ & $\%$ & $\mathbf{N}$ & $\%$ & $\mathbf{N}$ & $\%$ & & & & \\
\hline Negative & 14 & 28.6 & 6 & 14.6 & 20 & 22.2 & & & & \\
\hline Positive & 35 & 71.4 & 35 & 85.4 & 70 & 77.8 & 85.37 & 28.6 & 49.30 & 68.42 \\
\hline Total & 49 & 100.0 & 41 & 100.0 & 90 & 100.0 & $\begin{array}{r}\text { Overall A } \\
\text { Kappa }\end{array}$ & $\begin{array}{l}\text { greemen } \\
=0.112,\end{array}$ & $\begin{array}{l}\text { uracy) } \\
\text { lue) }=0\end{array}$ & $\begin{array}{l}3.33 \\
68\end{array}$ \\
\hline
\end{tabular}

Table (6): Sensitivity, specificity, positive predictive value (PPV) and negative predictive value (NPV) of QFT-GIT against TST among TB patients and contact group .

\begin{tabular}{|c|c|c|c|c|c|c|c|c|c|c|}
\hline \multirow{3}{*}{ QFT-GIT } & \multicolumn{6}{|c|}{ TST induration $(\geq 5 \mathrm{~mm})$} & \multirow{3}{*}{ Sensitivity } & \multirow{3}{*}{ Specificity } & \multirow{3}{*}{ PPV } & \multirow{3}{*}{ NPV } \\
\hline & \multicolumn{2}{|c|}{ Negative } & \multicolumn{2}{|c|}{ Positive } & \multicolumn{2}{|c|}{ Total } & & & & \\
\hline & $\mathbf{N}$ & $\%$ & $\mathbf{N}$ & $\%$ & $\mathbf{N}$ & $\%$ & & & & \\
\hline Negative & 11 & 39.3 & 9 & 14.5 & 20 & 22.2 & & & & \\
\hline Positive & 17 & 60.7 & 53 & 85.5 & 70 & 77.8 & 85.5 & 39.3 & 75.71 & 55.0 \\
\hline Total & 28 & 100.0 & 62 & 100.0 & 90 & 100.0 & $\begin{array}{r}\text { Overall A } \\
\text { Kappa }\end{array}$ & $\begin{array}{l}\text { greemen } \\
=0.291,\end{array}$ & $\begin{array}{l}\text { uracy } \\
\text { ue) }=\end{array}$ & 1.11 \\
\hline
\end{tabular}

*significant $\mathrm{p}<0.05$

\section{DISCUSSION}

Tuberculosis affects individuals of all age groups, but it is more common in middle-aged adults, that agreed with our findings. Malnutrition and low body mass index (BMI) level are risk factors for active TB infection [16]. However, in this study normal BMI was more common in patients. Moreover, smoking increasing the risk of the development of active TB [17]. This was applicable to our results that about $64.4 \%$ of TB patients are heavy smokers.

In the current study, QFT-GIT sensitivity with TST and ZN was relatively high at $85.5 \%$ and $85.37 \%$, respectively. The sensitivity results in this study agreed with other reported data in numerous studies [18,19]. However, the specificity of QFT-GIT to TST and ZN was $39.3 \%$ and $28.6 \%$, respectively. Cho et al. reported relatively low specificity of QFT-GIT at about $57.6 \%$ [20]. The low specificity in this study may be attributed to the high rate of positive QFT-GIT in contacts that indicated the spreading of LTBI. Besides, ZN stain is negative in all contacts that lower the agreement and accordingly the sensitivity of QFT-GIT with ZN. The overall sensitivity of QFT-GIT was $77.4 \%$ that was higher than the sensitivity of TST (63.2\%) in PTB patients. While, the overall specificities of the QFT-GIT and TST were $51.2 \%$ and $74.4 \%$, respectively.

Studies reported negative agreement results with QFT-/TST+ among contacts and explained these findings as a consequence of BCG vaccination [21,22]. However, in this study, high agreement results with $\mathrm{QFT}+\mathrm{TST}+$ were observed in patients and contacts $(86 \%$ and $84.2 \%$, respectively). Despite most of the patients and contacts were BCG vaccinated but both diagnostic tests in our study were not affected by BCG vaccination. 
IGRA is recommended to be used in immunocompromised as HIV-infected individuals as it is not affected by immunosuppression [23]. Furthermore, in this study, a positive HIV patient resulted in positive QFT-GIT that supported this finding.

After following up for contacts, two contacts with positive concordant results $(\mathrm{QFT}+\mathrm{TST}+)$ had developed active PTB within three months after sampling. Both were diabetic females; their ages 52 and 54 years, and their husbands had been infected with PTB. This finding supported that diabetes mellitus increases the risk of $\mathrm{TB}$ infection [24].

The TB incident cases are higher in high-risk groups when both TST and IGRA are positive [25]. For that, the approval and availability of IGRA could be a supportive screening test at high-risk contacts for LTBI. In this study, two patients with negative $\mathrm{ZN}$ and positive $\mathrm{LJ}$ developed positive results with QFT-GIT. For that, we recommend the use of QFT-GIT when the person is clinically suspected of TB but smear-negative or not able to produce sputum.

According to the ROC curve, cut-off points for QFT-GIT wereas chosen to be bigger than 1.53 $\mathrm{IU} / \mathrm{ml}$, which was also higher than that stated by the manufacturer $0.35 \mathrm{IU} / \mathrm{ml}$. The difference in cut-offs could be due to the difference in the studied population. A higher value of the cut-off resulted in increasing the specificity without a marked decrease in the sensitivity. This improves the use of QFT for the screening of latent TB in the contact group. Few studies reported the adjustment of the QFT-GIT cut-off value to diagnose active TB [26].

\section{CONCLUSION}

From this study, we concluded that QFT-GIT was positive among most patients and contacts. Evaluation of QFT-GIT in relation to TST results showed high sensitivity but relatively low specificity. Furthermore, the specificity of QFTGIT was improved by modifying the cut off values to higher levels. QFT-GIT assay could be used as an adjunctive diagnostic tool for patients with suspected TB when the conventional diagnostic methods fail. In addition, LTBI was likely to occur when both QFT-GIT and TST were positive. Early identifying and diagnosis of LTBI will aid in the elimination of TB and prevent the spread of resistant Mtb strains.
Ethical considerations: The Ethical Committee of the High Institute of Public Health, Alexandria University in Egypt approved the study. Our research obeyed the international guidelines of research, of the declaration of Helsinki.

Declaration of competing interest: The authors declare that there are no conflicts of interest.

Funding: No funding sources.

Acknowledgements: We appreciate the help of El-Maamourah hospital medical staff Dr. Somaya, Mrs. Zoba and Mrs. Gehan.

\section{REFERENCES}

1. World Health Organization. Global TB report. 2019.https://apps.who.int/iris/bitstream/handle/10 665/329368/9789241565714-eng.pdf (accessed 5 Oct2020).

2. World Health Organization. Country cooperation strategy for WHO and Egypt. 2018.https://apps.who.int/iris/bitstream/handle/10 665/137164/ccsbrief_egy_en.pdf?sequence=1\&is Allowed=y (accessed 5 Oct2020).

3. National Tuberculosis Control Program. Guide for nationaltuberculosis control program. Directorate general for chestdiseases, ministry of health and population, Arab Republicof Egypt. 2015.http://www.ccs.gov.eg/ntp/ (accessed 5 Oct2020).

4. World Health Organization. The stop TB strategy. Geneva. 2006. https://www.who.int /tb/publications/2010/strategy_en.pdf (accessed 5 Oct2020).

5. World Health Organization. Fact sheet: The global tuberculosis report. Geneva. 2018.https://www.who.int/news-room/factsheets/detail/tuberculosis (accessed 5 Oct2020).

6. Brodie D, Schluger NW. The diagnosis of tuberculosis. Clin Chest Med 2005; 26:247-71.

7. Sterling TR, Njie G, Zenner D, Cohn DL, Reves $\mathrm{R}$, Ahmed A, et al. Guidelines for the Treatment of Latent Tuberculosis Infection: Recommendations from the National Tuberculosis Controllers Association and CDC, 2020. Am J Transplant 2020; 20:1196-1206.

8. Farhat M, Greenaway C, Pai M, Menzoes D. False-positive tuberculin skin tests: what is the absolute effect of BCG and non-tuberculous mycobacteria? Int J Tuberc Lung Dis 2006; 10:1192-204.

9. Chandrasekaran P, Mave V, Thiruvengadam K, Gupte N, Shivakumar SVB, Hanna LE, et al. Tuberculin skin test and QuantiFERON-Gold In 
Tube assay for diagnosis of latent TB infection among household contacts of pulmonary TB patients in high TB burden setting. PLoS One 2018; 13:1-16.

10. Sester M, Sotgiu G, Lange C, Giehl C, Girardi E, Migliori GB et al. Interferon-gamma release assays for the diagnosis of active tuberculosis: a systematic review and meta-analysis. Eur Respir J 2011; 37:100-111.

11. Centers for Disease Control. TB Centers of Excellence Professional Resources \& Tools TB CDC. 2018. https://www.cdc.gov/tb/ education/tb_ coe/default.htm (accessed 5 Oct2020).

12. International Union against Tuberculosis and Lung Disease (IUAT). Sputum Examination for tuberculosis by direct microscopy in low income countries. In: $5^{\text {th }}$ ed.; 2000.

13. Global Laboratory Initiative. Mycobacteriology laboratory manual. 2014. https://www.who.int/tb/laboratory/mycobacteriol ogy-laboratory-manual.pdf (accessed 5 Oct2020).

14. Lee AK. A simple guide to IBM SPSS statistics for version 20.0. Student ed. Belmont, California: Wadsworth, Cengage Learning. 2013.

15. Kotz S, Balakrishnan N, Read CB, Vidakovic VB. Encyclopedia of statistical sciences. 2nd ed. Hoboken, New Jersey: Wiley-Interscience. 2006.

16. Soh AZ, Chee CBE, Wang YT, Yuan JM, Koh WP. Diabetes and body mass index in relation to risk of active tuberculosis: A prospective population-based cohort. Int J Tuberc Lung Dis 2019; 23:1277-1282.

17. Cole B, Nilsen DM, Will L, Etkind SC, Burgos M, Chorba T, et al. Essential components of a public health tuberculosis prevention, control, and elimination program: Recommendations of the advisory council for the elimination of tuberculosis and the national tuberculosis controllers association. MMWR Recomm Reports 2020; 69:1-27.

18. Aichelburg MC, Rieger A, Breitenecker F, Pfistershammer $\mathrm{K}$, Tittes $\mathrm{J}$, Eltz $\mathrm{S}$, et al. Detection and prediction of active tuberculosis disease by a whole-blood interferon-gamma release assay in HIV-1-infected individuals. Clin Infect Dis 2009; 48:954-62.

19. Whitworth HS, Badhan A, Boakye AA, Takwoingi Y, Rees-Roberts M, Partlett C, et al. Clinical utility of existing and second-generation interferon- $\gamma$ release assays for diagnostic evaluation of tuberculosis: an observational cohort study. Lancet Infect Dis 2019; 19:193202.

20. Cho K, Cho E, Kwon S, Im S, Sohn I, Song S et al. Factors Associated with Indeterminate and False Negative Results of QuantiFERON-TB Gold In-Tube Test in Active Tuberculosis. Tuberc Respir Dis 2012; 72:416-25.

21. Machado A, Emodi K, Takenami I, Finkmoore BC, Barbosa T, Carvalho J et al. Analysis of discordance between the tuberculin skin test and the interferon-gamma release assay. Int $\mathbf{J}$ Tuberc Lung Dis 2009; 13:446-53.

22. Won D, Park JY, Kim HS, Park Y. Comparative results of QuantiFERON-TB gold in-tube and QuantiFERON-TB gold plus assays for detection of tuberculosis infection in clinical samples. J Clin Microbiol 2020; 58:1-8.

23. Alrajhi S, Germain P, Martel M, Lakatos $\mathrm{P}$, Bessissow T, Al-Taweel T, et al. Concordance between tuberculin skin test and interferongamma release assay for latent tuberculosis screening in inflammatory bowel disease. Intest Res 2020; 18:306-314.

24. Ugarte-Gil C, Alisjahbana B, Ronacher K, Malherbe ST, Cioboata R, Malherbe ST, et al. Diabetes mellitus among pulmonary tuberculosis patients from four TB-endemic countries: the TANDEM study. Clin Infect Dis 2020; 70: 780788.

25. Campbell JR, Winters N, Menzies D. Absolute risk of tuberculosis among untreated populations with a positive tuberculin skin test or interferongamma release assay result: Systematic review and meta-analysis. BMJ 2020; 368:1-10.

26. Chang PC, Wang PH, Chen KT. Use of the Quantiferon-tb gold in-tube test in the diagnosis and monitoring of treatment efficacy in active pulmonary tuberculosis. Int J Environ Res Public Health 2017; 14:236.

27. Thompson AM, Stonebridge PA. Clinical Practice 08: CLINICAL PRACTICE 08. $\mathrm{Br} J$ Surg 2002; 89:79-79.

28. Mei Z, Grummer-Strawn LM, Pietrobelli A, Goulding A, Goran MI, Dietz WH. Validity of body mass index compared with other bodycomposition screening indexes for the assessment of body fatness in children and adolescents. Am J Clin Nutr 2002; 75:978-85. 